\title{
Creep-fatigue behavior of aluminum alloy-based metal matrix composite
}

\author{
Daniele Barbera ${ }^{\mathrm{a}}$, Hao Feng Chen ${ }^{\mathrm{a}, *}$, Ying Hua Liu ${ }^{\mathrm{b}}$ \\ ${ }^{a}$ Department of Mechanical \& Aerospace Enginnering, University of Strathclyde,Montrose Street 76, Glasgow, G1 1XJ, UK \\ ${ }^{b}$ Department of Engineering Mechanics, Tsinghua University, Beijing, 100084, China
}

\begin{abstract}
Metal Matrix Composite (MMC) represents a valuable option as structural material for different type of structures and components. Despite this they struggle to become widely adopted due to expensive manufacturing process and complex microstructural behaviour. When subjected to cyclic load conditions the structural response of MMC is not trivial, and becomes even more difficult when high temperature load is involved. Different failure mechanisms would happen and they are originated by the different material properties between the fibre and surrounding matrix. Among all, the mismatch of thermal expansion coefficient is recognized to be the dominant one. The significantly differing coefficients of thermal expansion between ceramic and metal give rise to micro thermal stresses, which enhance the initiation of matrix micro cracks. Their performance under varying load and high temperature is complex, and hence it is difficult to have a clear understanding of the structural responses, especially when fatigue and creep damages become the main failures of MMCs. To improve current understanding of the relationship between creep fatigue interaction of MMCs, the history of thermal and mechanical loading, and the creep dwell period, a highly accurate but robust direct simulation technique on the basis of the Linear Matching Method (LMM) framework has been proposed in this paper, and been applied to model the fatigue and creep behaviour of MMCs. A homogenised FE model is considered in all analyses, which consist of continuous silicon carbide fibres embedded in a square 2024T3 aluminium alloy matrix array. Various factors that affect creep and fatigue behaviours of composites are analysed and discussed, including effects of the applied load level, dwell period and temperature on the MMC's performance. The effects of reversed plasticity on stress relaxation and creep deformation of MMC are investigated, and the behaviours of cyclically enhanced creep and elastic followup are presented. A detailed study of the creep ratchetting mechanism is also performed with the concentration on the impact of temperature and different loading conditions. The accuracy of the proposed method has been verified by detailed incremental finite element analyses using the commercial finite element solver Abaqus. Such verifications further improve the understanding of the failure mechanisms identified and discussed in this work.
\end{abstract}

Keywords: Linear Matching Method (LMM); Creep; Fatigue; Cyclic Plasticity; Metal Matrix Composite (MMC)

\section{Introduction}

The increasing demand of machines operating at high level of efficiency requires high operating temperatures, and for particular application also a light weight design. Metal Matrix Composites (MMCs) are composite materials which are capable of delivering the aforementioned requirements. Different types of reinforcement can be introduced in the metal matrix, including randomly dispersed particles, short fibres and homogenously aligned long fibres. This work is concentrated on the latter type of reinforcement, which has a high strength on the fibre direction and low weight ratio as well. However these advantages are seriously downsized by creep behaviour, thermal fatigue, manufacturing processes and environment problems like oxidation [1]. Especially creep fatigue behaviour becomes an area of research interest, due to the lack of a unified and universal method to asses it, although different standard codes were developed for the assessment of creep fatigue life of high temperature component, including ASME BPV code and UK R5 [2, 3].

When creep is present, the structure's response to a cyclic loading condition changes dramatically [4-6], with respect to the low temperature case. Due to the induced residual stresses by creep and plasticity, a closed stress

\footnotetext{
* Corresponding author. Tel.: +44-141-548- 2036.

E-mail address: haofeng.chen@strath.ac.uk (Hao Feng Chen)
} 
strain cycle may be formed when the reverse plastic strains completely recover the inelastic strain created during loading and creep dwell periods. With this situation, the lifetime of the MMCs is dominated by the combined damages from cyclically enhanced creep and increased fatigue by the stress relaxation during the dwell period. Alternatively, the hysteresis loop may become non-closed if the creep strains become too large for the reverse plastic strains to recover or vice versa. This leads to a critical failure mechanism called creep ratchetting, which is similar to the plastic ratchetting, for both the inelastic strain will be accumulated during each load cycle. However, the accumulation of inelastic strain for creep ratchetting is driven by either the creep strain or stress relaxation during the dwell period. In order to evaluate creep fatigue interactions and combined damages of MMCs under cyclic load and high temperature condition, various factors that affect creep and fatigue behaviours of composites need to be investigated, including effects of the applied cyclic load level, dwell period and temperature on the MMC's performance.

Numerical simulations and modelling of fibre or particle reinforced aluminium based MMC have been performed by many researchers [7-15], in particular for the low cycle fatigue damage due to the cyclic plasticity, and creep rupture under high temperature condition. Traditional Finite Element Analysis was adopted, using for each case the most convenient material model, able to fit the experimental results. The micromechanical model was also used to study the size effect of fibre or particle on the MMC response. The Linear Matching Method (LMM), as a powerful Direct Method for the shakedown and ratchet analysis, has been used to investigate the shakedown and ratchetting response of fibre [16] or particle [17] reinforced MMC. However very little research focused on the creep fatigue interaction of $\mathrm{MMC}$ on a numerical prospective, and great efforts are necessary when simulating different interacting mechanisms.

The LMM has been recently extended for the evaluation of fatigue creep interaction and validated by $[4,5]$ and further used for a more practical application, i.e. creep fatigue life assessment of weldment [18-20]. But despite this no study on creep fatigue interaction of MMCs was performed by using the LMM. Therefore, the aim of this paper is to adopt the latest extension of the LMM [4] to evaluate the steady state cycle response of a silicon carbide fibre reinforced 2024T3 aluminium alloy based MMC, subjected to a cyclic thermal and mechanical load with a creep dwell between the loading and unloading phase. The interaction between all the aforementioned failure mechanisms is described and investigated for different loading conditions. This work is intended to be a general and fundamental attempt in understanding the microstructural response to high temperature environment and cyclic loading.

\section{Numerical Procedures}

\subsection{General overview of the thermo-mechanical cyclic problem}

Consider an Elastic Perfectly Plastic (EPP) body with a volume V and a surface S, which is subjected to a general cyclic load condition. On such body volume is applied a cycling temperature $\lambda_{\theta} \theta(x, t)$ instead on the surface a constant load $\lambda_{p} P(x, t)$ acting over part of the structure's surface $S_{T}$. The remaining surface is constrained to have no displacement. The time variation considered over a typical cycle is $0 \leq t \leq \Delta t$. Corresponding to these loading histories there exists a linear elastic stress history:

$$
\hat{\sigma}_{i j}{ }^{e}(x, t)=\lambda_{\theta} \hat{\sigma}_{i j}^{\theta}(x, t)+\lambda_{p} \hat{\sigma}_{i j}^{p}(x, t)
$$

where $\hat{\sigma}_{i j}^{\theta}$ and $\hat{\sigma}_{i j}^{p}$ denotes the varying elastic stresses due to $\theta(x, t)$ and $P(x, t)$, respectively. By selecting the proper values for $\lambda_{\theta}$ and $\lambda_{p}$ a whole class of loading histories can be considered. The general stress field for the cyclic problem involves three different components, the elastic, the constant and the changing residual stress fields.

$$
\sigma_{i j}(x, t)=\hat{\sigma}_{i j}^{e}(x, t)+\bar{\rho}_{i j}(x)+\rho_{i j}^{r}(x, t)
$$

The history $\rho_{i j}^{r}$ is the change in the residual stress during the cycle and must be zero at both the start and end of each load cycle, so that the stress and strain rate histories are asymptotic to the cyclic state. 


\subsection{An Extended LMM Direct Steady Cycle Analysis considering creep}

In the present work an extended procedure of the LMM Direct Steady Cycle Analysis (DSCA) is adopted to evaluate the low cycle fatigue response with creep dwell. As in other works the LMM procedure requires as input a series of linear elastic solutions, generated at discrete time points within the cycle where a significant stress range occurs and hence the most relevant plastic strain. Such strategy is quite significant in terms of efficiency, because it saves computing time by targeting the steady state cycle directly and neglecting insignificant loading conditions which are assumed to lie in the von Mises yield surface, comparing with other cycle-by-cycle analysis methods which must consider the entire load history.

The aim of this extended DSCA procedure is to calculate the cyclic stress history at the steady state due to the accumulation of the residual stress field by either plastic or creep responses. The associated inelastic plastic or creep strains are also evaluated for the steady state load cycle. The extended DSCA procedure is based on a series of iterative cycles which are defined as $\mathrm{m}=1,2 \ldots \mathrm{M}$. Within each iterative sub-cycle, there will be a series of increments $N$, corresponding to each time points within the cycle ranging from $\mathrm{n}=1,2 \ldots \mathrm{N}$. Each individual varying residual stress $\Delta \rho_{i j}^{r}\left(x, t_{n}\right)_{m}$ associated with each elastic solution $\hat{\sigma}_{i j}^{e}\left(x, t_{n}\right)$ at sub-cycle $\mathrm{m}$ will be calculated by the extended DSCA procedure in an iteratively way $[4,5]$. Upon reaching a converged solution, the constant residual stress term from equation (2) can be determined by

$$
\bar{\rho}_{i j}(x)=\sum_{m=1}^{M} \sum_{n=1}^{N} \Delta \rho_{i j}^{r}\left(x, t_{n}\right)_{m}
$$

The accumulated residual stress for $n^{\text {th }}$ load instance at $m^{\text {th }}$ cycle of iterations can be defined as;

$$
\rho_{i j}^{r}\left(x, t_{n}\right)_{m}=\sum_{k=1}^{m-1} \sum_{n=1}^{N} \Delta \rho_{i j}^{r}\left(x, t_{n}\right)_{k}+\sum_{k=1}^{n} \Delta \rho_{i j}^{r}\left(x, t_{k}\right)_{m}
$$

A flowchart of the LMM extended DSCA procedure is presented in Fig. 1, which shows how to evaluate steady state plastic and creep behaviors of structures in an iterative way. For the load instance $t_{n}$ without creep dwell period, the plastic strain amplitude $\Delta \varepsilon_{i j}^{p}\left(x, t_{n}\right)$ can be calculated by;

$$
\Delta \varepsilon_{i j}^{p}\left(x, t_{n}\right)=\frac{1}{2 \bar{\mu}\left(x, t_{n}\right)}\left[\hat{\sigma}_{i j}^{e}\left(x, t_{n}\right)^{\prime}+\rho_{i j}^{r}\left(x, t_{n}\right)^{\prime}\right]
$$

where notation ( ' ) refers to the deviator component of stresses and $\bar{\mu}$ is the iterative shear modulus [4]. When adopting the Ramberg-Osgood (RO) material model, this plastic strain amplitude can be used to update the iterative yield stress. For the load instance with creep dwell period $\Delta t$, the effective creep strain $\Delta \bar{\varepsilon}^{c}$ can be calculated by equation (6) when considering a time hardening creep constitutive equation (17) in [4].

$$
\Delta \bar{\varepsilon}^{c}=\frac{B(n-1) \Delta t^{m+1}\left(\bar{\sigma}_{s}-\bar{\sigma}_{c}\right)}{\left(\frac{1}{\bar{\sigma}_{c}^{n-1}}-\frac{1}{\bar{\sigma}_{s}^{n-1}}\right)(m+1)}
$$

where $B, m$ and $n$ are the creep constants of the material. $\bar{\sigma}_{c}$ denotes the creep flow stress, which is the sum of the start-of-dwell stress $\bar{\sigma}_{s}$ and the residual stress $\Delta \rho_{i j}^{r}$ induced during the dwell period. The creep flow stress can be evaluated by equation (25) in [4], using the information of the creep strain rate at the end of dwell time, which is calculated by equation (23) and (24) in [4]. The calculation of the residual stress $\Delta \rho_{i j}^{r}$ at each increment is through 
the solution of a formulated linear problem (10) as described in [4]. When the procedure is completed the residual stress field is obtained and the iterative shear modulus $\bar{\mu}_{m}\left(x, t_{n}\right)$ is updated at each sub-cycle for each load instance $t_{n}$ by adopting the linear matching equation;

$$
\bar{\mu}_{m+1}\left(x, t_{n}\right)=\bar{\mu}_{m}\left(x, t_{n}\right) \frac{\sigma_{y}^{R}\left(x, t_{n}\right)_{m}}{\bar{\sigma}\left(\hat{\sigma}_{i j}^{e}\left(x, t_{n}\right)+\rho_{i j}^{r}\left(x, t_{n}\right)_{m}\right)}
$$

where $\bar{\mu}_{m}\left(x, t_{n}\right)$ is the iterative shear modulus at the sub-cycle $m$ for $n$th load instance. $\sigma_{y}^{R}\left(x, t_{n}\right)_{m}$ is the iterative vonMises yield stress for RO material model or yield stress for the Elastic Perfectly Plastic (EPP) material model at load instance $t_{n}$. This yield stress $\sigma_{y}^{R}\left(x, t_{n}\right)_{m}$ will be replaced by creep flow stress $\bar{\sigma}_{c}$ when considering a load instance involving creep relaxation due to the introduced dwell period. At the end of each sub-cycle, the convergence will be checked. If the convergence criterion is not satisfied a subsequent sub-cycle starts, otherwise the results are outputted to provide all the crucial parameters for creep fatigue assessment.

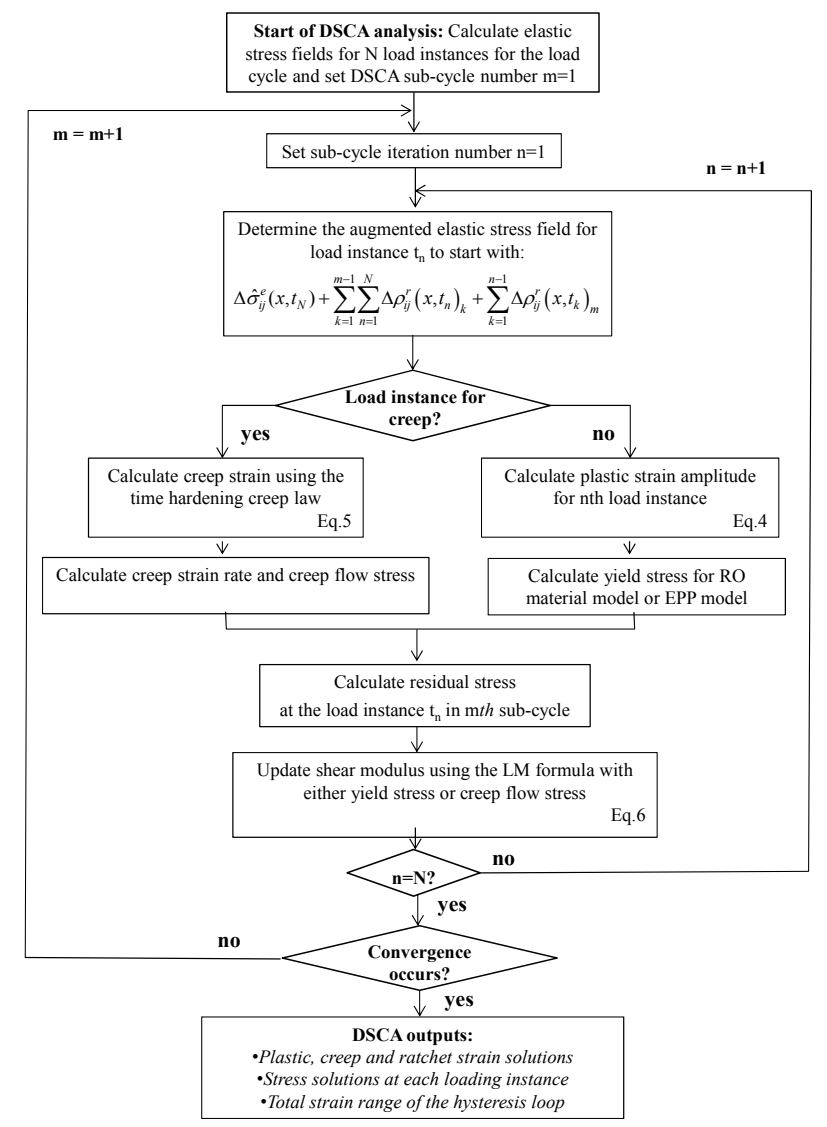

Fig. 1. Flow chart illustrating the LMM extended DSCA numerical procedure.

\section{Finite element model}

\subsection{Metal Matrix Composite numerical model}


A long fibre reinforced MMC is analysed in this work. Due to the periodic dispersion of the fibres in the matrix a unit cell can be identified for the micromechanical modelling. The MMC unit cell is subjected to a constant mechanical load on the right external face and uniform cycling temperature from 0 to $\theta_{0}$ in the body (Error! Reference source not found.). To assess the creep effect on the cyclic behaviour of MMC, a dwell period $\Delta t$ is introduced at each load cycle as shown in the Fig. 2. Due to geometric symmetries a quarter of the unit cell is adopted with two planes of symmetry applied as boundary conditions, in addition to the plain condition on the two external faces to introduce the periodic constraints.
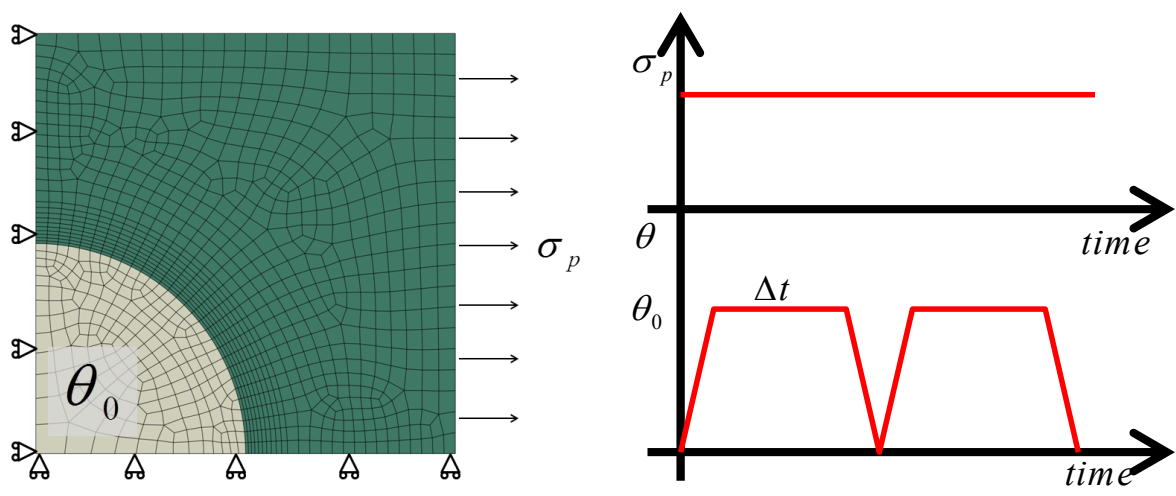

Fig. 2. Finite element model of the MMC unit cell and loading history.

The mesh is composed of 1039 8-node biquadratic plane strain quadrilateral elements, with a reduced integration scheme. The model is composed of two parts, a left corner spherical fibre and a surrounding metal matrix (Error! Reference source not found.). Due to the interaction between the fibre and the matrix a refined mesh is adopted in the "Interaction Boundary" where the failure mechanisms are mostly expected.

Table 1 MMC material properties.

\begin{tabular}{ccc}
\hline & $\mathrm{Al}_{2} \mathrm{O}_{3}$ Fibre & $\mathrm{Al} 2024 \mathrm{~T} 3$ Matrix \\
\hline$E[M P a]$ & 450000 & 73000 \\
$v$ & 0.15 & 0.33 \\
$\alpha$ & $4 E^{-6}$ & $2.3 E^{-5}$ \\
$\sigma_{y}[\mathrm{MPa}]$ & 10000 & 345 \\
\hline
\end{tabular}

The material properties for both the matrix and fibre are reported in Table 1. Creep behaviour is evaluated using a time hardening creep constitutive relationship;

$$
\dot{\varepsilon}^{c r}=A \cdot \sigma^{n} \cdot t^{m}
$$

where $n$ is the stress exponent, $m$ is the time exponent for the primary creep stage and $A$ is the power law multiplier. Creep is considered only for the matrix and the data for tensile creep is taken from [21] and reported in Table 2.

Table 2 Creep parameters A, $\mathrm{n}$ and $\mathrm{m}$ for 2024T3 aluminium alloy.

\begin{tabular}{ccccc}
\hline & $150^{\circ} \mathrm{C}$ & $175^{\circ} \mathrm{C}$ & $200^{\circ} \mathrm{C}$ & $225^{\circ} \mathrm{C}$ \\
\hline$A$ & $0.763 \cdot 10^{-12}$ & $3.461 \cdot 10^{-12}$ & $4.079 \cdot 10^{-12}$ & $5.1186 \cdot 10^{-12}$ \\
$n$ & 3.246 & 3.299 & 3.395 & 3.5526 \\
$m$ & -0.303 & -0.573 & -0.535 & -0.5199 \\
\hline
\end{tabular}


In order to verify the LMM results, ABAQUS step-by-step analyses are used and the single operating load cycle consists of three ABAQUS load steps. The first one is a *STATIC step, which represents the loading phase where both temperature and mechanical load are applied. Then a *VISCO step is present to simulate the creep dwell time where mechanical load and temperature are constant. To implement equation (8) during the second step a user defined *CREEP subroutine is necessary, and the time-hardening formulation is adopted. The third step is a *STATIC step representing the unloading phase, where the mechanical load is constant and the temperature goes to zero.

\section{Results and discussions}

\subsection{Effect of creep dwell on hysteresis loop}

In order to provide a benchmark to define reasonable cyclic load conditions for the creep fatigue assessment of MMC, a shakedown limit interaction curve was calculated as shown in Fig. 2 by using the LMM shakedown analysis method, where a reference uniform cycling temperature range from $0^{\circ} \mathrm{C}$ to $\theta_{0}$ (where $\theta_{0}=200^{\circ} \mathrm{C}$ ) is applied over the entire model. The ordinate and abscissa axes in Fig. 2 show the temperature and mechanical load, normalised to the reference temperature $\theta_{0}$ and yield stress $(345 \mathrm{MPa})$ of matrix respectively.

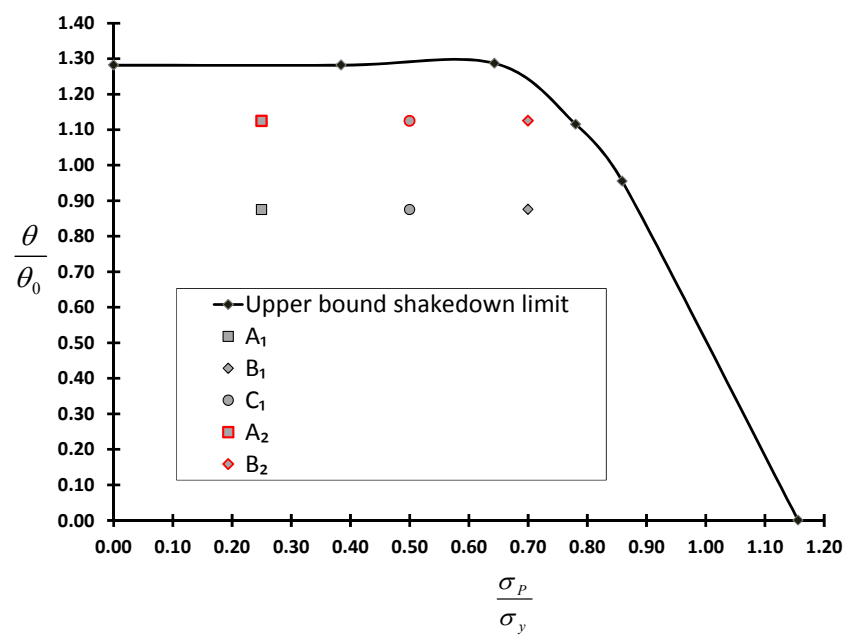

Fig. 2. Shakedown limit for the MMC under constant mechanical load and cycling thermal load.
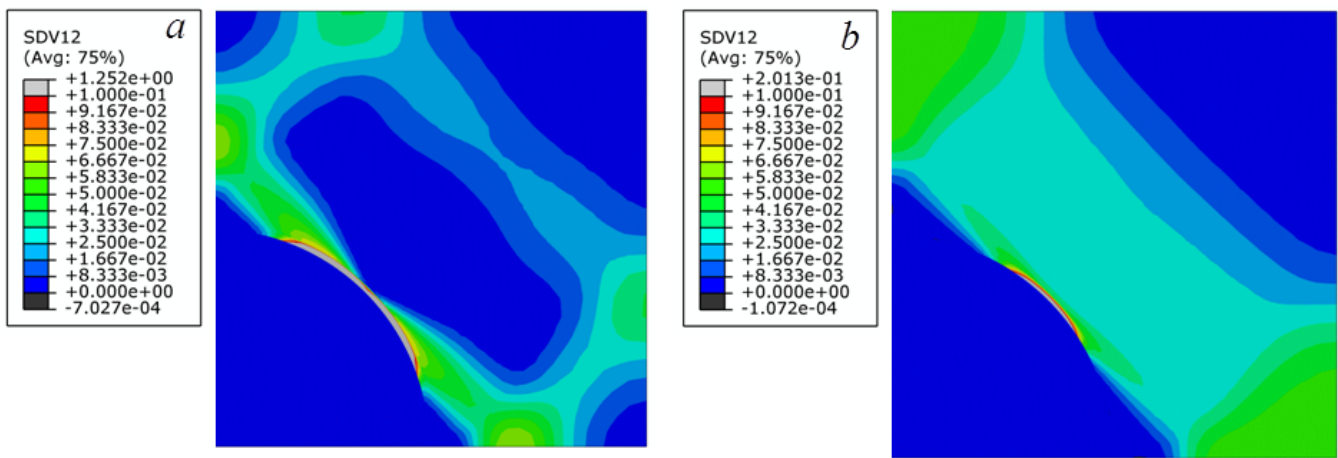

Fig. 3. Effective plastic strains at different cycling load points 
The adopted LMM analysis is also able to estimate the overall failure mechanism of MMC including the most critical location, by showing the contour of cyclic plastic strain range. Fig. 3a shows the cell response to a cyclic load point at $(0.7,1.0)$ (Fig. 2), whereas Fig. $3 \mathrm{~b}$ corresponds to the limit load. It is clear from Fig. 3 that the "Interaction Boundary" is the most critical location, and this will be the location where the fatigue and creep damage will accumulate, ultimately initiating cracking in the matrix. The evaluation of creep fatigue behavior of MMCs is performed by a series of analyses considering six cyclic load points inside the shakedown limit: $\mathrm{A}_{1}(0.25,0.875), \mathrm{A}_{2}(0.25,1.125), \mathrm{B}_{1}(0.7,0.875), \mathrm{B}_{2}(0.7,1.125), \mathrm{C}_{1}(0.5,0.875)$ and $\mathrm{C}_{2}(0.5,1.125)$ as shown in Fig. 2. If without creep effect, all these cyclic load points within the shakedown limit should exhibit shakedown behavior only. The aim of our analysis is to investigate how the cyclic behavior of MMC changes with creep response due to the introduced high temperature dwell period. In order to understand the creep-fatigue interaction, each load point is evaluated for different dwell times 1,100,1000 and 10000 hours, respectively.

Four hysteresis loops are generated and presented in Error! Reference source not found. for cyclic load points $\mathrm{A}_{1}$ and $\mathrm{C}_{1}$, where the blue and red line correspond respectively to a dwell time of 1 hour and 100 hours at $175^{\circ} \mathrm{C}$. For a dwell time of 1 hour the closed hysteresis loop is present only for $A_{1}$, instead for $C_{1}$ a small total strain increment is present. Creep affects both cases and enhances the unloading plasticity, but no plastic straining occurs during loading due to the total stress level since it is below the yield. The loop shape changes when a larger dwell time is considered, and non-closed loop behavior is observable also for $A_{1}$. In Error! Reference source not found., the accumulation of total strain is entirely driven by the creep strain. Under such conditions the damage caused by creep is important even for low level primary load as seen for load point $A_{1}$.
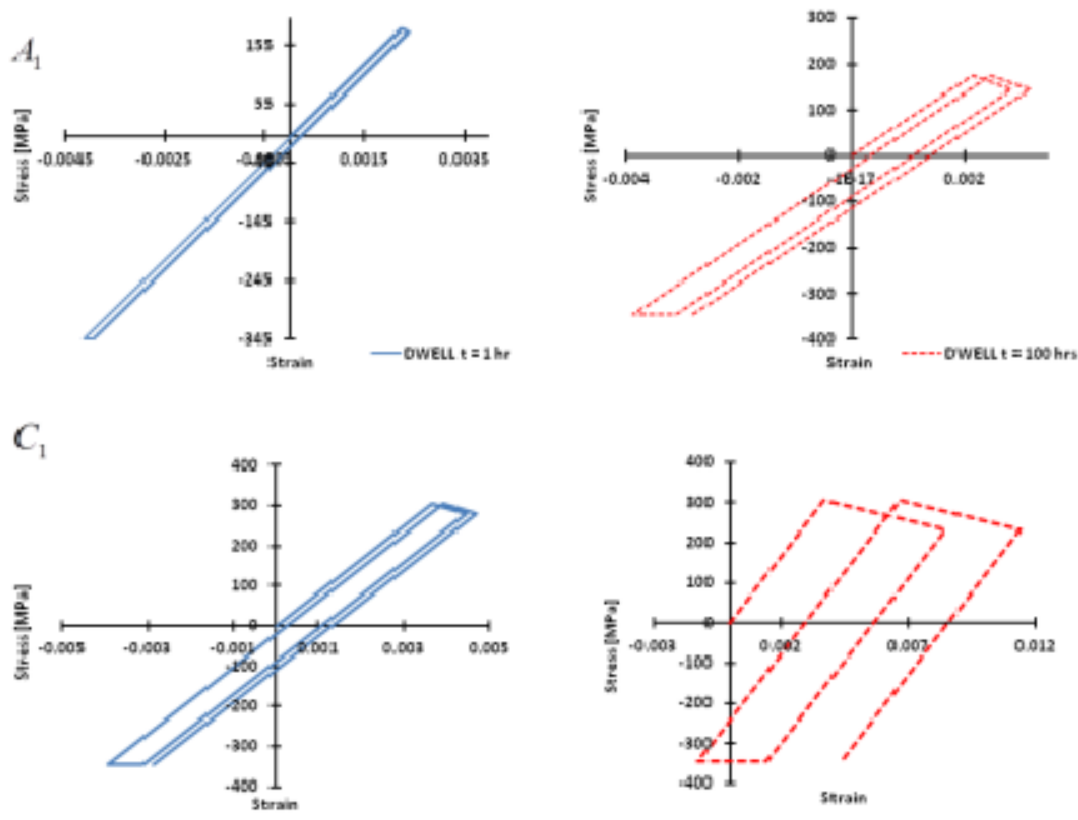

Fig. 4. Stress-strain responses at steady state at location with the maximum plastic strain for different dwell time for load points $A_{1}$ and $C$ 

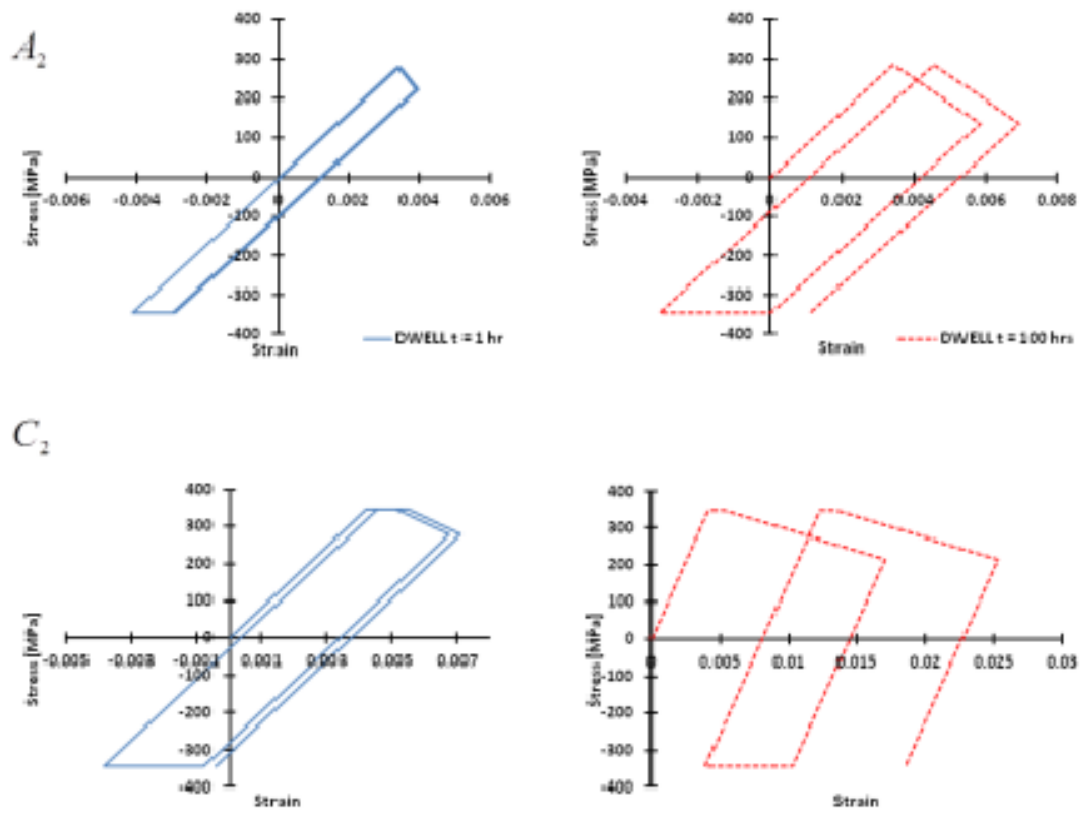

Fig. 5. Response of the steady state stress-strain path at location with the maximum plastic strain for different dwell time for load points $\mathrm{A}_{2}$ and $\mathrm{C}_{2}$

Error! Reference source not found. shows the MMC response to the cyclic load points $A_{2}$ and $C_{2}$ for different dwell times at $225^{\circ} \mathrm{C}$. The load point $\mathrm{A}_{2}$ with smaller mechanical load also exhibits a closed loop for a 1 hour dwell time (blue line) as the load point $\mathrm{A}_{1}$ (Error! Reference source not found.), but with a larger strain range due to the higher thermal load applied. Conversely load point $\mathrm{C}_{2}$ with larger mechanical load shows a small creep ratchetting mechanism even for 1 hour dwell time. Furthermore for cyclic load point $\mathrm{C}_{2}$ a small plastic strain also accumulates during the loading phase. Such behavior is due to the larger mechanical load and the accumulated residual stresses during the cycle which lead some regions to yield also during the loading phase. For the 100 hours of dwell time both loading points behave in a similar way, where creep ratchetting become the dominant mechanism.

In order to have a complete overview of structure response to such cyclic loading conditions, cyclic load points $B_{1}$ and $B_{2}$ (Fig. 2) are investigated and the corresponding stress strain responses at the steady state are presented in Error! Reference source not found.. For both dwell times, both points $\mathrm{B}_{1}$ and $\mathrm{B}_{2}$ show the plastic loading phase and creep ratchetting behaviour due to the very large mechanical load. However point $\mathrm{B}_{2}$ has a higher strain levels due to the higher temperature of $225^{\circ} \mathrm{C}$ applied. When the dwell time is increased from 1 hour to 100 hours, creep strain is increased greatly for both load points, and more significant creep ratchetting mechanism is present. 

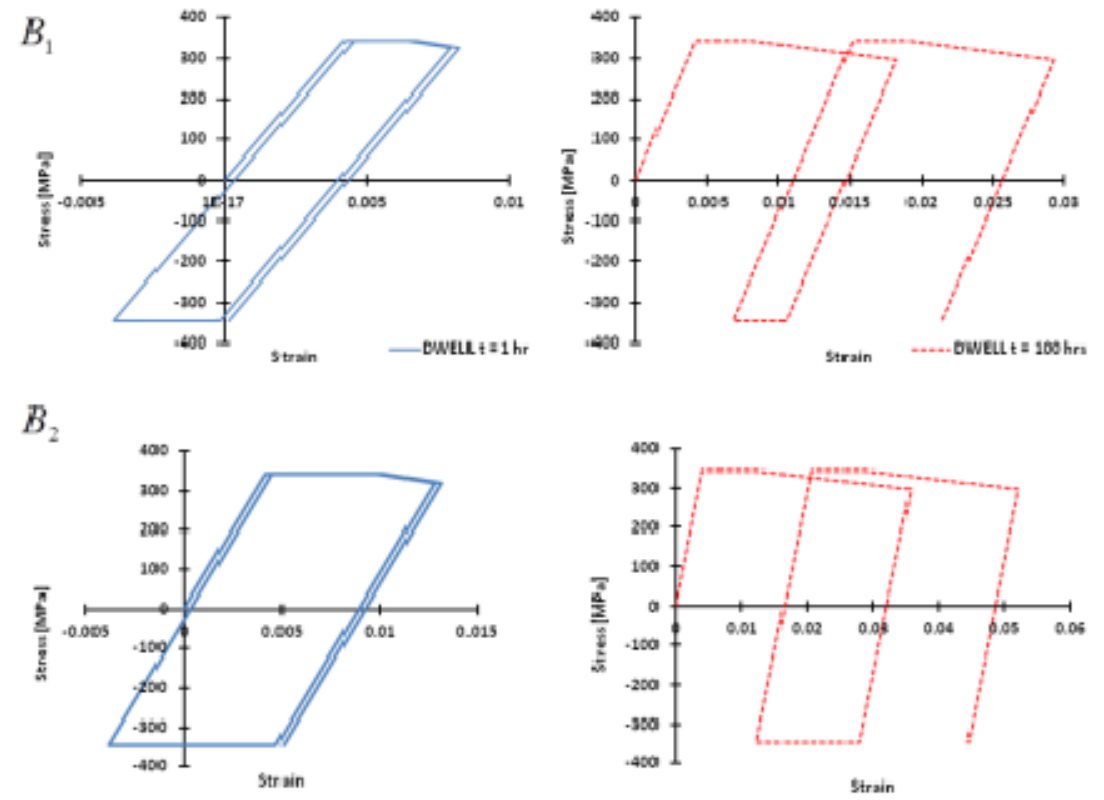

Fig. 6. Response of the steady state stress-strain path at location with the maximum plastic strain for different dwell time for load points B1 and B2.

The detailed effects of different creep dwell times on plastic strains for both cyclic load points $\mathrm{B}_{1}$ and $\mathrm{B}_{2}$ are reported in Figure 8. Figure 8a and Figure 8b show the plastic strain range during loading phase for point $\mathrm{B}_{1}$ and $\mathrm{B}_{2}$ respectively, which involves a small and localized area in the "Interaction Boundary". When the creep dwell time is increased the plastic region does not increase significantly and still highly localized, but with a greater plastic strain magnitude. For point $\mathrm{B}_{2}$ with higher temperature of $225^{\circ} \mathrm{C}$ the plastic region becomes bigger and also slightly increases for longer creep dwell. A similar trend is shown by Figure $8 \mathrm{c}$ and Figure $8 \mathrm{~d}$ for cyclic load points $\mathrm{B}_{1}$ and $\mathrm{B}_{2}$ respectively, where the plastic strain at unloading phase is reported. Both Fig.s confirm the major plastic damage occurs at the unloading phase, and involves a quite large area of matrix. The increase of both the dwell time and the thermal load enhances such behaviour significantly by dramatically increasing the plastic strain magnitude as shown in Figure $8 \mathrm{c}$ and Figure $8 \mathrm{~d}$. For both load points $\mathrm{B}_{1}$ and $\mathrm{B}_{2}$, the creep ratchetting behaviour becomes very significant as it is enhanced by the high level of primary load. Dwell time is also crucial for the cell response to the cyclic load. 

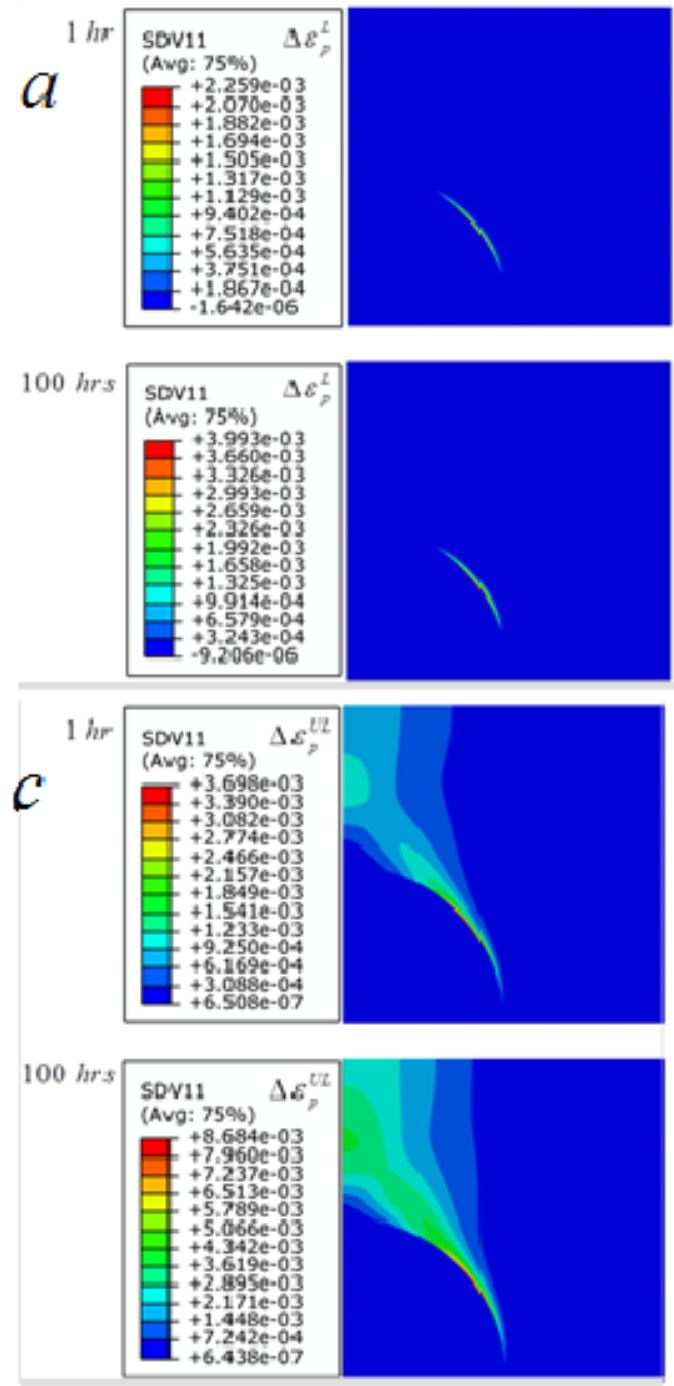
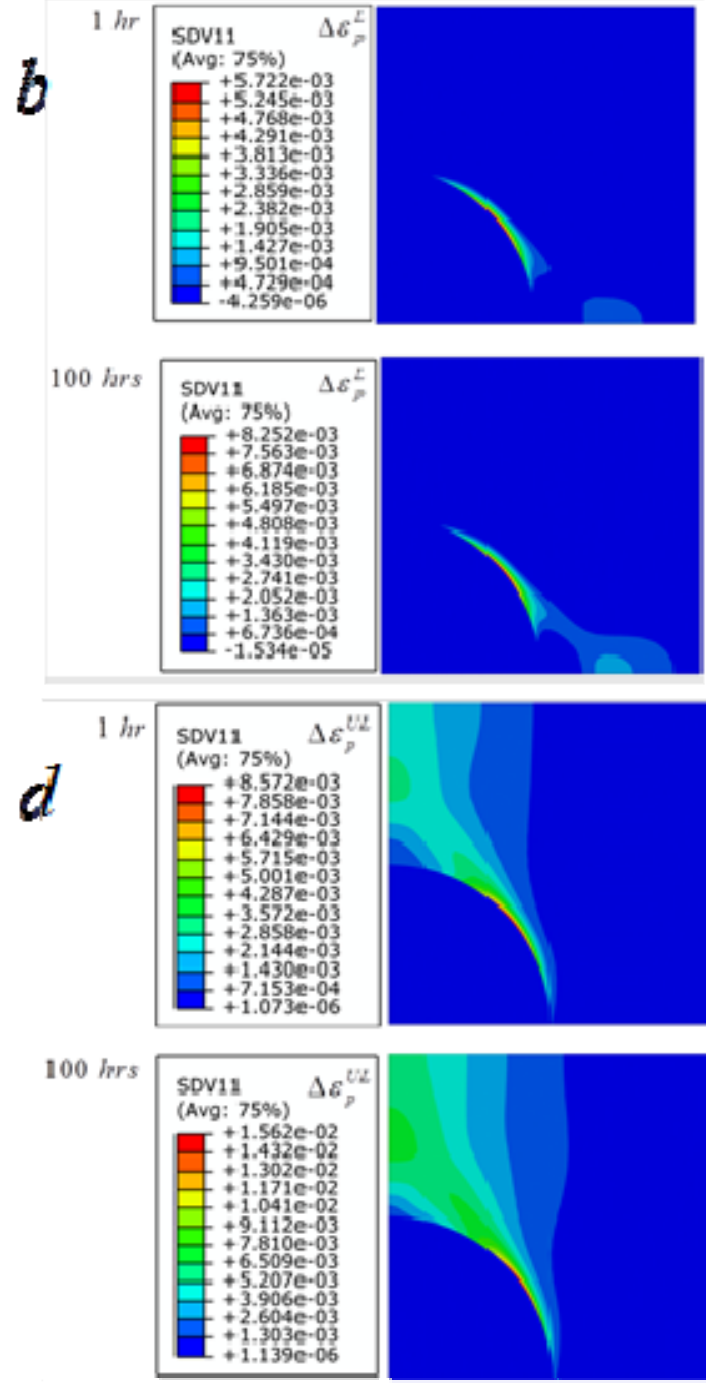

Fig. 7. Effect of dwell time on plastic strain increments at loading and unloading for cyclic load points $\mathrm{B}_{1}$ and $\mathrm{B}_{2}$

All the results confirm that creep ratchetting mechanisms is affected by two key parameters, dwell time and the primary load level. The analyses performed for cyclic load case $A_{1}$ and $A_{2}$ showed a closed hysteresis loop. The increase of dwell time drastically changed the $\mathrm{MMC}$ response, introducing an evident creep strain accumulation even for such cases. In order to confirm the importance of the primary load on the creep ratchetting behavior, the pure cyclic thermal load case is investigated, i.e. $\frac{\sigma_{P}}{\sigma_{y}}=0.0 \frac{\theta}{\theta_{0}}=1.0$.

This loading condition is investigated by considering varying dwell times from 1 hour to a maximum of 10000 hours. The calculated hysteresis loops for different dwell times are shown in Error! Reference source not found.. It is evident that when there is no primary load, despite the increase of creep dwell, the secondary thermal load is not capable of causing creep ratchetting in the MMCs. However, the increase of dwell time enhances the creep strain and the stress relaxation during the dwell period and consequentially enhances the plastic behavior during the unloading phase. This will inevitably increase the total strain range of the closed hysteresis loop, until a limiting state is reached, where all thermal stresses are fully relaxed to zero, no further creep strain is induced, and hence there is no additional enhancement of reverse plasticity during the unloading phase. As presented in Error! 
Reference source not found., when there is no primary load, the creep strain occurred during the dwell period will be fully recovered by the plastic strain during the unloading phase, leading to a closed hysteresis loop.

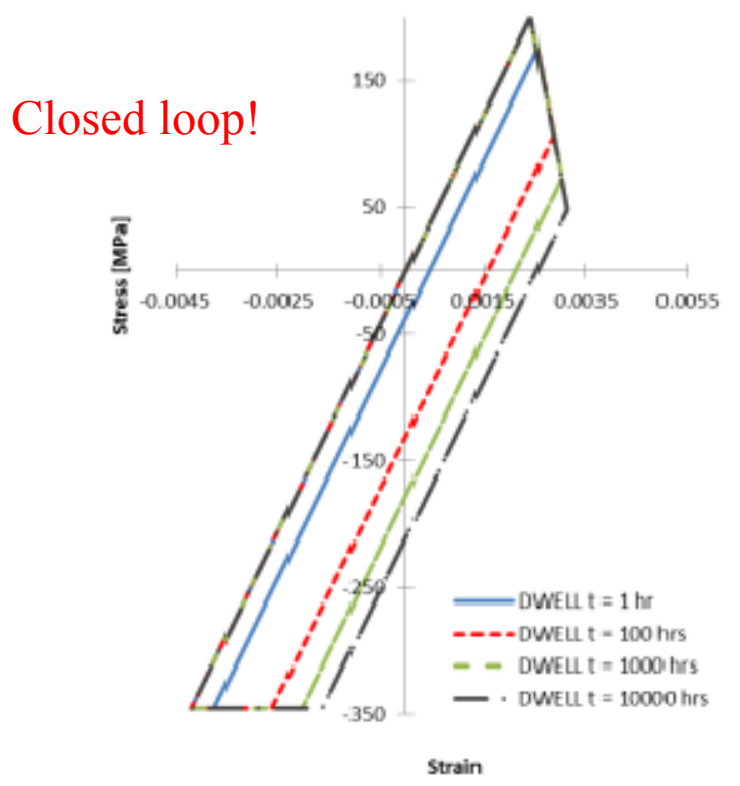

Fig. 9. Response of the steady state stress-strain path at location with the maximum plastic strain for different dwell times.

In Fig. 10 an overview of the stress fields at the end of creep and unloading phase for different dwell times is presented. Due to the material mismatch, at both loading phases the highest stress of matrix develops around the fibre, starting from the "Interaction Boundary". When the creep dwell is increased, a significant stress relaxation occurs and the affected area becomes larger. Longer dwell time allows wider area to yield during the unloading phase, as shown in Fig. 10. The increase of creep dwell also causes higher plastic strain during unloading, and such mechanism makes the size of the hysteresis loop larger.

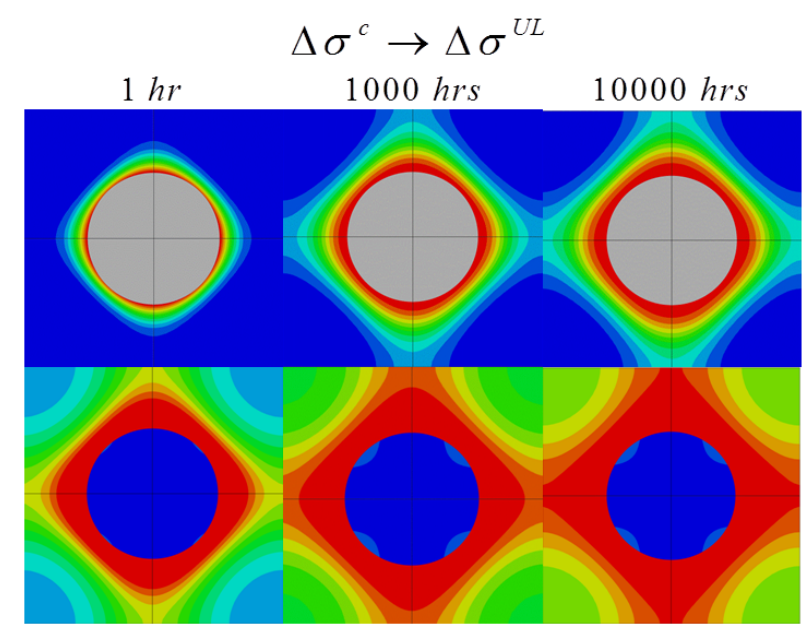

Fig. 10. Effect of dwell time on stress state at the end of creep and unloading phase respectively. 


\subsection{Further studies on the effect of creep dwell on hysteresis loop and verification}

To further understand the effect of dwell time on the cyclic response of MMC, the plot of magnitudes of maximum plastic strain increments during loading and unloading phases against the applied dwell time is presented in Fig. 11a, and the plot of maximum creep ratchet strain (i.e. the accumulated inelastic strain) per cycle against the applied dwell time is given in Fig. 11b. It can be seen clearly from Fig. 11a that when the applied dwell time is more than 1000 hours, the plastic strain magnitudes at both loading and unloading phases nearly keep unchanged. This behaviour occurs as the creep stress at the end of the dwell period reaches a steady state. By this point the creep stress cannot relax anymore and the plastic strain magnitude during the unloading phase cannot increase with the further increase of the dwell time. However it is observed from Fig. 11b that the maximum creep ratchet strain almost increases linearly with the dwell time when the applied dwell time is more than 1000 hours. This highlights the effects of creep dwell time on both the shape of hysteresis loop, and the creep-fatigue life of the MMC. For a long dwell time, creep damage dominates and a creep ratchetting mechanism occurs. This highlights the importance of the dwell time for the life assessment of component operating under such loading conditions, even when the operated loading condition is below the shakedown limit.

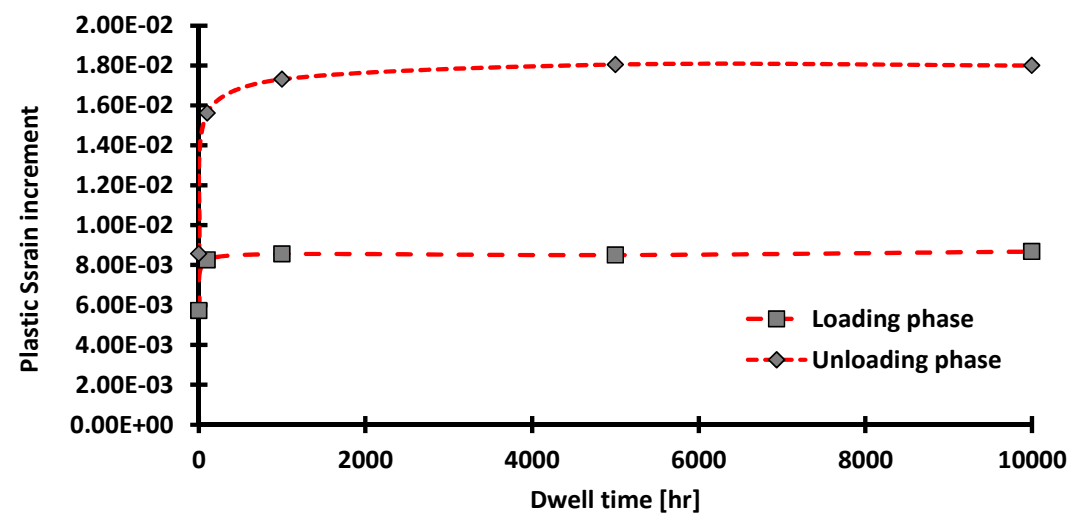

(a)

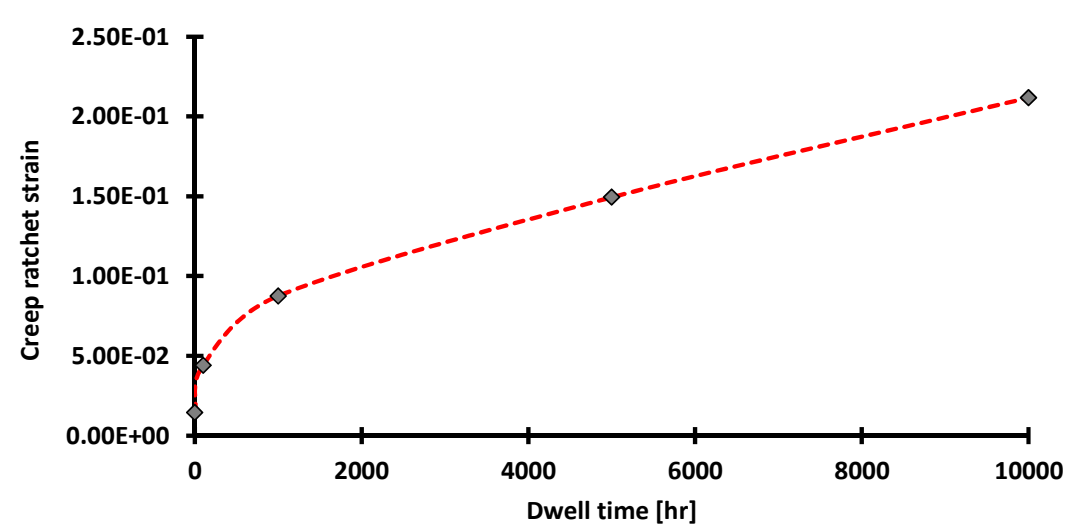

(b)

Fig. 11 a) Plastic strain increments, and b) Creep ratchet strain per cycle against dwell time at cyclic loading point $B_{2}$.

During the dwell period, both the stress relaxation and creep strain accumulation are observed for MMC. This is related to a phenomenon called elastic follow-up [2], and is typically quantified by an elastic follow up factor Z, defined by the ratio of the creep strain increment to the elastic strain increment during stress relaxation. Under constant displacement loading, the stress relaxation results in no change in the total strain, as creep strain replaces 
elastic strain with time, where $Z=1$. The elastic follow-up factor is known to be influenced by loading conditions [2, 6], and larger primary loads combined with longer dwell times produce larger Z. For the MMC investigated, the detailed elastic follow up factors at the location of maximum creep strain for different dwell times and 4 considered cyclic load conditions are presented in Table 3. This shows how the magnitude of the primary load affects the $Z$ factor. When the MMC is subjected to a low mechanical load $\left(A_{1} A_{2}\right)$ only moderate increases occur when the dwell time is increased, whereas radical changes are observed when the primary load is increased $\left(\mathrm{B}_{1}\right.$ and $\left.\mathrm{B}_{2}\right)$.

Table 3 Values of elastic follow-up factor at location with maximum creep strain, for different loading conditions and creep dwell times.

\begin{tabular}{ccccc}
\hline $\begin{array}{c}\text { Load } \\
\text { point }\end{array}$ & $\begin{array}{c}\mathrm{Z} \\
\Delta t=1\end{array}$ & $\begin{array}{c}\mathrm{Z} \\
\Delta t=100\end{array}$ & $\begin{array}{c}\mathrm{Z} \\
\Delta t=1000\end{array}$ & $\begin{array}{c}\mathrm{Z} \\
\end{array}$ \\
\hline $\mathrm{A}_{1}$ & 2.45 & 2.91 & 3.80 & 6.15 \\
$\mathrm{~B}_{1}$ & 7.65 & 22.8 & 51.8 & 128 \\
$\mathrm{~A}_{2}$ & 1.72 & 2.35 & 3.77 & 8.04 \\
$\mathrm{~B}_{2}$ & 11.4 & 60.4 & 159 & 441 \\
\hline
\end{tabular}
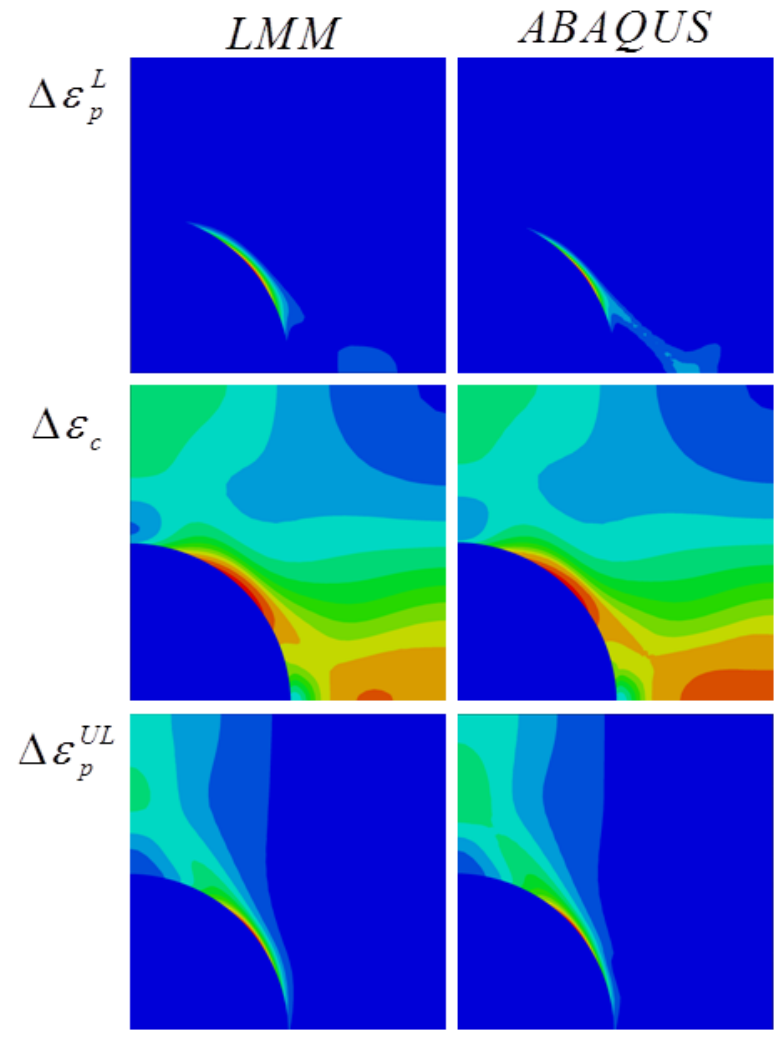

Fig. 12. Comparisons between LMM and ABAQUS step-by-step analysis for strain increments at loading, creep and unloading phase. 
Table 4 Comparison between LMM and Step-by-Step Abaqus analyses, for different cyclic loading points.

\begin{tabular}{lllllll}
\hline & $\Delta \varepsilon_{p}^{L}$ & \multicolumn{3}{c}{$\Delta \varepsilon_{c}$} & $\Delta \varepsilon_{p}^{U L}$ \\
\hline Cyclic load point & LMM & ABAQUS & LMM & ABAQUS & LMM & ABAQUS \\
\hline $\mathrm{A}_{1}$ & 0.0 & 0.0 & $2.21 E^{-4}$ & $2.53 E^{-4}$ & $1.80 E^{-4}$ & $2.00 E^{-4}$ \\
$\mathrm{~B}_{1}$ & $2.26 E^{-3}$ & $2.01 E^{-3}$ & $1.76 E^{-3}$ & $1.74 E^{-3}$ & $3.70 E^{-3}$ & $3.51 E^{-3}$ \\
$\mathrm{~A}_{2}$ & 0.0 & 0.0 & $1.20 E^{-3}$ & $1.25 E^{-3}$ & $1.13 E^{-3}$ & $1.20 E^{-3}$ \\
$\mathrm{~B}_{2}$ & $5.72 E^{-3}$ & $5.15 E^{-3}$ & $3.22 E^{-3}$ & $3.14 E^{-3}$ & $8.57 E^{-3}$ & $8.15 E^{-3}$ \\
\hline
\end{tabular}

In order to verify the LMM results a direct comparison with the ABAQUS step-by-step analyses is performed. Three quantities are considered in the verification procedure, the creep strain increment $\left(\Delta \varepsilon_{c}\right)$, the plastic strain increment at loading $\left(\Delta \varepsilon_{p}^{L}\right)$ and the plastic strain increment at unloading $\left(\Delta \varepsilon_{p}^{U L}\right)$. Direct comparisons of contours and magnitudes of these plastic and creep strains obtained by the LMM and ABAQUS step-by-step analyses are given in Fig. 12 and Error! Reference source not found., respectively, and a perfect agreement is observed. It is evident that the LMM is capable of producing accurate solutions to estimate the cyclic response of MMC to the applied cyclic load condition with creep dwell. Furthermore, it is worth noting that the LMM creep fatigue analysis is much more efficient than the standard ABAQUS step-by-step analysis procedure. Based on a standard PC, the computational CPU cost to solve one cyclic loading case for any the dwell time required by the LMM analysis is approximately 149 seconds (150 total increments), against the 792 seconds ( 810 total increments) and 1268 seconds (2600 total increments) required by the ABAQUS step-by-step analysis for 1 hour and 10000 hours dwell times respectively. This comparison verifies the efficiency superiority of LMM.

\subsection{Discussions on MMC damaging and response to the cyclic load}

Among 6 cyclic loading points shown in Fig. 2, the most critical one is $\mathrm{B}_{2}$. Hence for this loading point a complete cell view is presented in Error! Reference source not found.a and Error! Reference source not found.b for the discussion. In previous sections it is well established that creep dwell time affects dramatically the structure response, due to the stress relaxation and redistribution, which are particularly damaging and responsible for the plasticity during the unloading and loading phase when the primary load level is high enough. Error! Reference source not found.a shows the stress distribution at the end of the creep dwell for two cases, 1 hour and aluminium alloy metal matrix composite 1000 hours of dwell time. The associated residual stress during the creep dwell makes it possible to yield regions which normally don't exhibit a plastic behaviour. This is highlighted by Error! Reference source not found.b where the plastic strain increment at unloading phase is reported. Both the plastic strain magnitude and area at unloading phase largely increases by longer dwell times. Due to the transverse direction of the mechanical load, the reinforcement fibre does not improve the tensile strength of MMC significantly under such load condition, which is the most critical load condition the structure may experience. The most dangerous mechanism shows plasticity in both loading and unloading phase. In such condition creep and creep ratchetting become extremely damaging when the dwell time increases. 

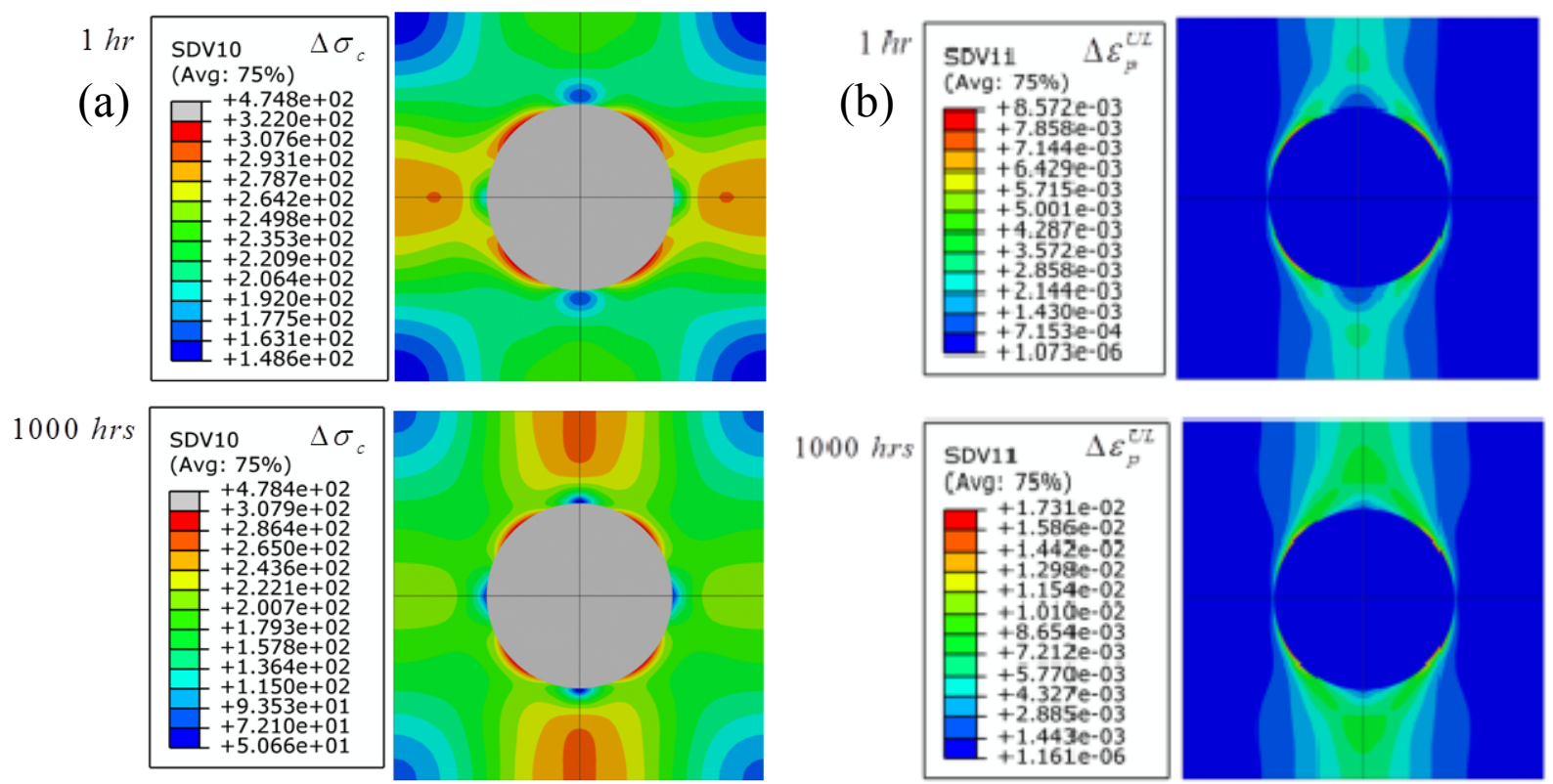

Fig. 13 a) Effect of dwell time on the stress distribution for the complete unit cell at the end of creep dwell, for cyclic load point B2, b) Effect of dwell time on the plastic strain increment of the complete unit cell during unloading phase, for cyclic load point B2

The effect of dwell time on the strain evolution is presented in Fig. 14, where the plastic and creep strains contours are shown for different dwell times. The loading phase is not affected by the increase of the dwell duration, because it starts after the tensile peak. Instead the unloading phase is remarkably enhanced by the increase of the creep dwell, which increases the stress drop at the most critical location, and enhances the reverse plasticity by increasing the total strain range. Furthermore, the creep strain increases remarkably over the different dwells analysed. For this particularly dangerous cyclic loading condition $\left(\mathrm{B}_{2}\right)$, the matrix experiences a large stress redistribution during the creep dwell and also a high level of stress during both the creep and unloading phase (Fig. 15). Such a high level of stress makes the creep damage dominant for dwell times up to 1000 hours. Instead for dwell time up to 10000 hours classical monotonic creep rupture occurs. The creep rupture failure initiates always in the interface area but rapidly involves the entire surrounding matrix. Then it is not capable of withstanding the applied load condition, and a fast increase of the creep strain is expected due to the increasing creep damage. It is important to underline that these failure analyses are performed within the shakedown limit. Without the presence of the creep dwell none of the aforementioned failure mechanisms can be observed. 


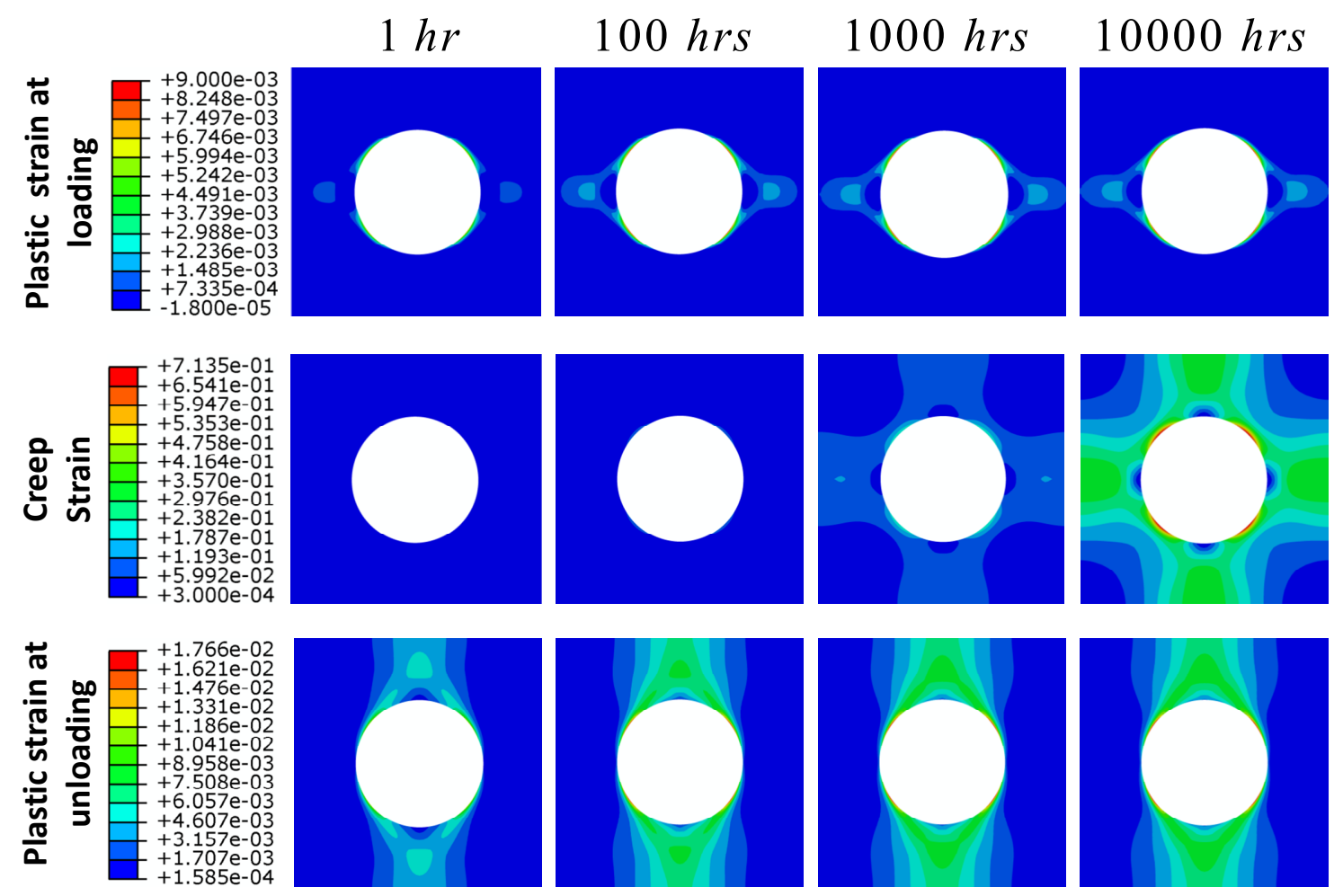

Fig. 14. Strain contours at loading, creep and unloading for a uniform cycling temperature $\theta_{0}=225^{\circ} \mathrm{C}$ and a constant mechanical load $\sigma_{\mathrm{p}}=241.5$ MPa for different dwell times.
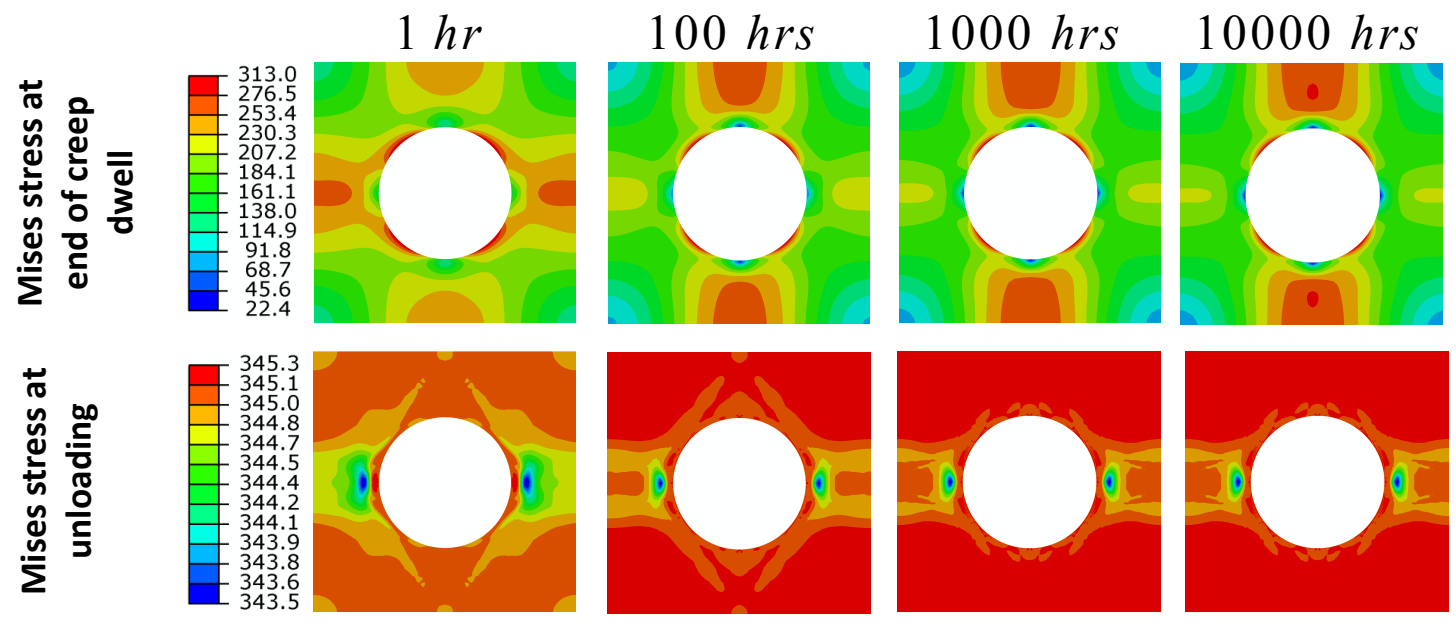

Fig. 15. Stress contours at end of the creep dwell and unloading phase for a uniform cycling temperature $\theta_{0}=225^{\circ} \mathrm{C}$ and a constant mechanical load $\sigma_{\mathrm{p}}=241.5 \mathrm{MPa}$ for different dwell times.

\subsection{Creep Ratchetting failure in the MMCs}

Creep ratchetting is a dangerous mechanism, which can interact with creep and fatigue and it may become dominant. Fig. 16 shows the creep ratchetting interaction diagram, which is useful to understand the response of the microstructure. The creep strain and net plastic strain, which is the difference between the plastic strain at loading 
and unloading phase, are displayed on the vertical and horizontal axes respectively. Closed loop is possible only if the creep strain is fully recovered by the net plastic strain. However this closed loop condition is remarkably affected by both the dwell time and the stress relaxation. The closed loop limit can be represented by a 45 degree slope line as shown in Fig. 16. The cyclic loading points $\mathrm{A}_{1}, \mathrm{~B}_{1}, \mathrm{C}_{1}$ are investigated for increasing dwell times. Only for short hold period, a closed loop is possible especially for high mechanical load level (up to 1 hour). Otherwise the results diverge on the upper part of the limit (Fig. 16). This means that the creep-ratcheting mechanism is creep strain dominated.

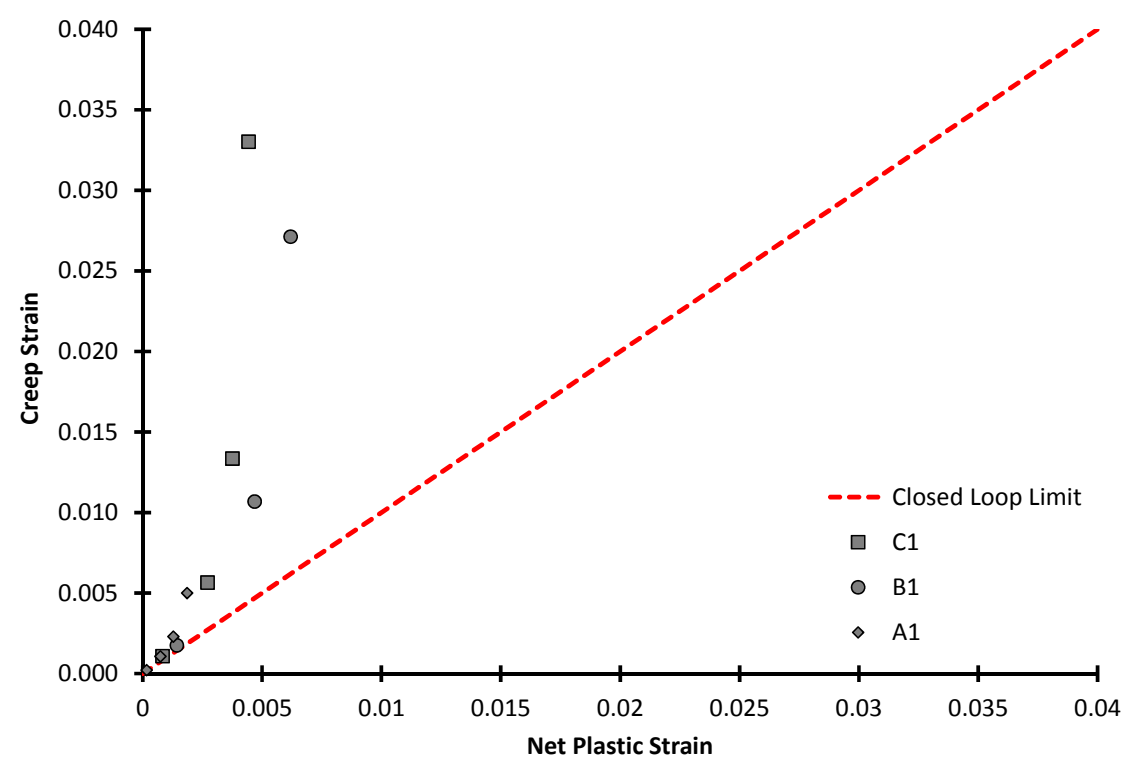

Fig. 16. Creep ratchetting interaction diagram for different cyclic loading points at increasing creep dwells

If the saturated cycle is an open loop, the number of cycle to failure due to the creep ratcheting can be evaluated using the simple strain ductility exhaustion equation [22], which is characterized by the ratio between the tensile strain to fail and the calculated ratchet strain per cycle. The creep ratchetting strains per cycle at two temperature conditions are shown in Fig. 17 for different mechanical loads. For both temperature conditions, it is shown that no ratchetting mechanism occurs when the mechanical load is zero, and the increase of such ratchetting strain per cycle has the same dependency on the applied mechanical load.

The effect of temperature on the creep ratchetting strain per cycle has also been shown in Fig. 17 against the normalised transverse mechanical load. For a normalised mechanical load of 0.5 the ratchetting strain per cycle increases from $0.7 \%$ to $1.4 \%$ for the 1000 hours dwell time when the temperature increases from 150 and $175^{\circ} \mathrm{C}$. Despite this it has been observed that the creep damage becomes dominant for longer dwell time and high mechanical load, and it is enhanced by higher temperatures. 

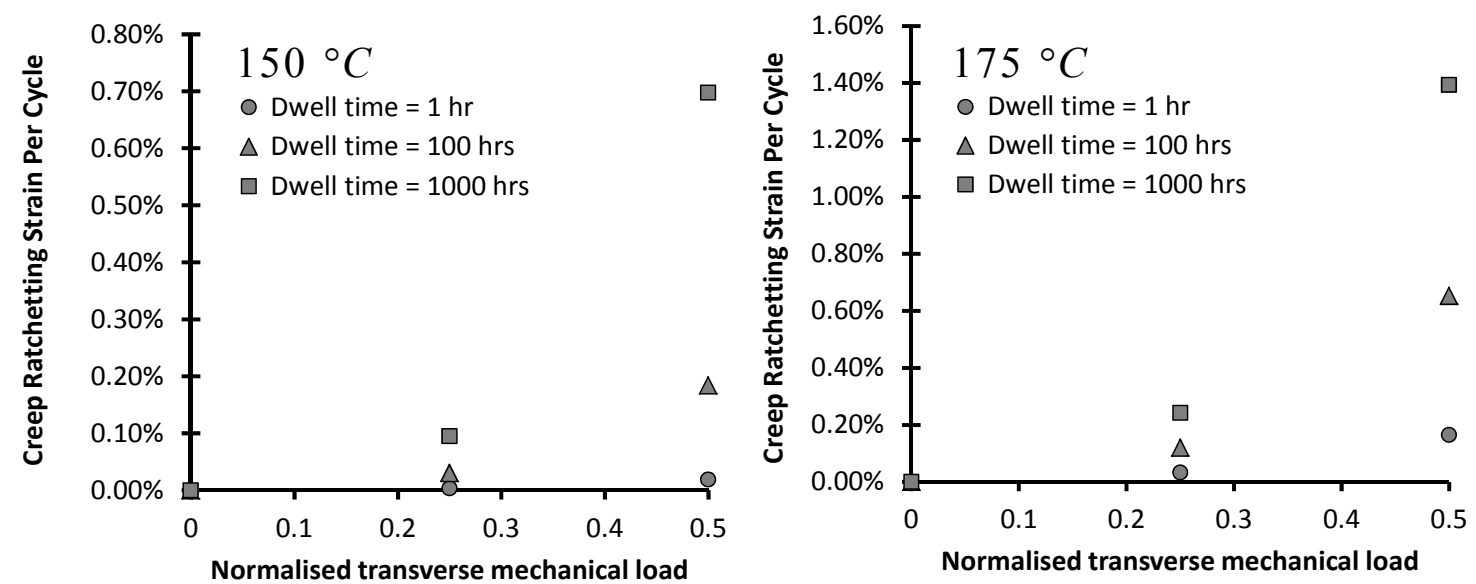

Fig. 17. Creep Ratchetting Strain per cycle at 150 and $175^{\circ} \mathrm{C}$ for different transverse constant mechanical load, normalised by the yield of the matrix.

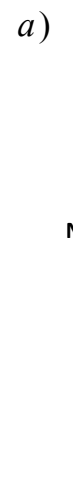

b)
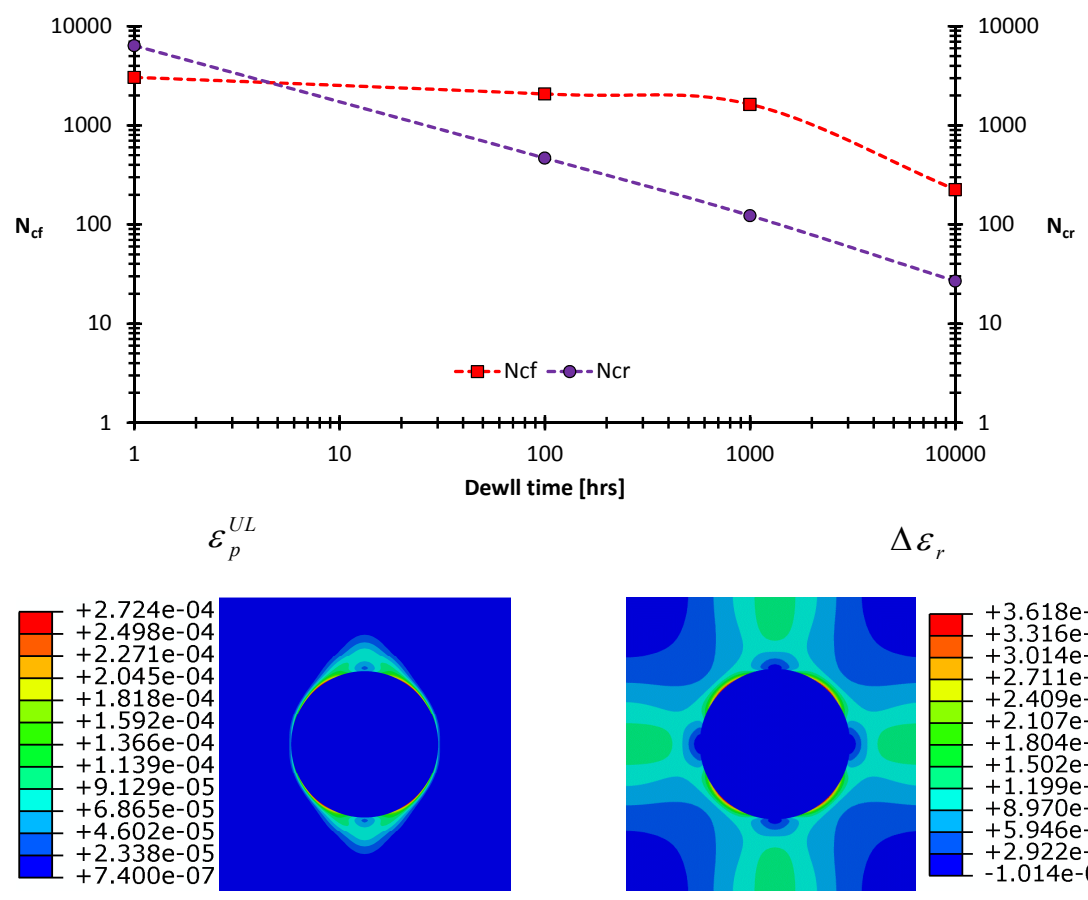

$\Delta \varepsilon_{r}$

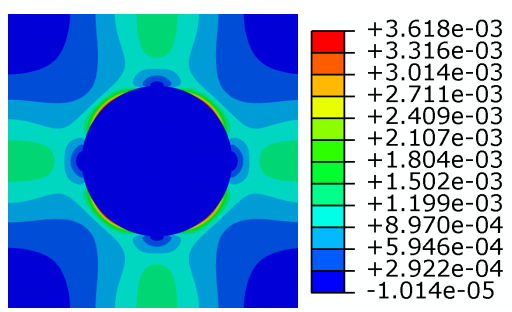

Fig. 18 a) Creep-fatigue life and creep ratchetting life against dwell time, b) contours of the plastic strain at unloading phase and the creepratchetting strain per cycle for a cyclic temperature of $150^{\circ} \mathrm{C}$ and a constant mechanical load 0.25 time the yield of the matrix.

The creep-fatigue life and creep ratchetting life against dwell time are shown in Fig. 18a for a cyclic temperature of $150{ }^{\circ} \mathrm{C}$. Up to 1000 hours, creep-fatigue life $\left(\mathrm{N}_{\mathrm{cf}}\right)$ is almost independent on dwell time and the fatigue damage dominates due to the low temperature of $150{ }^{\circ} \mathrm{C}$ considered, making the creep damage negligible. For dwell times longer than 1000 hours creep damage becomes significant, and competes with the damage caused by fatigue. The number of cycles to failure calculated using a strain ductility $\left(\mathrm{N}_{\mathrm{cr}}\right)$ approach are higher than the number of cycles to failure due to creep-fatigue interaction $\left(\mathrm{N}_{\mathrm{cf}}\right)$ for dwell time up to 10 hours. After this threshold of 10 hours creep ratchetting becomes dominant and causes the failure rather than the creep-fatigue interaction. In such a case the 
damage is associated with a large change in the size of cross-section area due to the material necking. A proof of this creep ratchetting mechanism is shown in the contours presented in Fig. 18b, where both the plastic strain at the unloading phase (left) and the ratchet strain increment per cycle (right) are presented. The magnitude of ratchet strain shown in Fig. 18b is larger than the plastic strain that occurs during the most dangerous cyclic phase. This means that the damage caused by the creep ratchetting is more significant than the damage produced by creep and fatigue interaction. In Fig. 19a, the creep-fatigue life and creep ratchetting life are reported against the dwell time for a temperature of $175^{\circ} \mathrm{C}$. For all the dwell times studied creep ratchetting is always less damaging than the combined damage due to fatigue and creep. For such a cyclic loading condition the driving fatigue and creep failure mechanism is the creep-fatigue interaction for intermediate dwell (up to 100 hours) and creep dominated for longer dwell periods (larger than 1000 hours). Fig. 19b presents the contours of the plastic strain at the unloading phase and the creep ratchetting strain increment per cycle. For this loading case the two quantities are comparable, but the damage caused by the creep ratchetting strain per cycle is still negligible respect to that caused by combined damage due to the creep and fatigue interaction.

a)

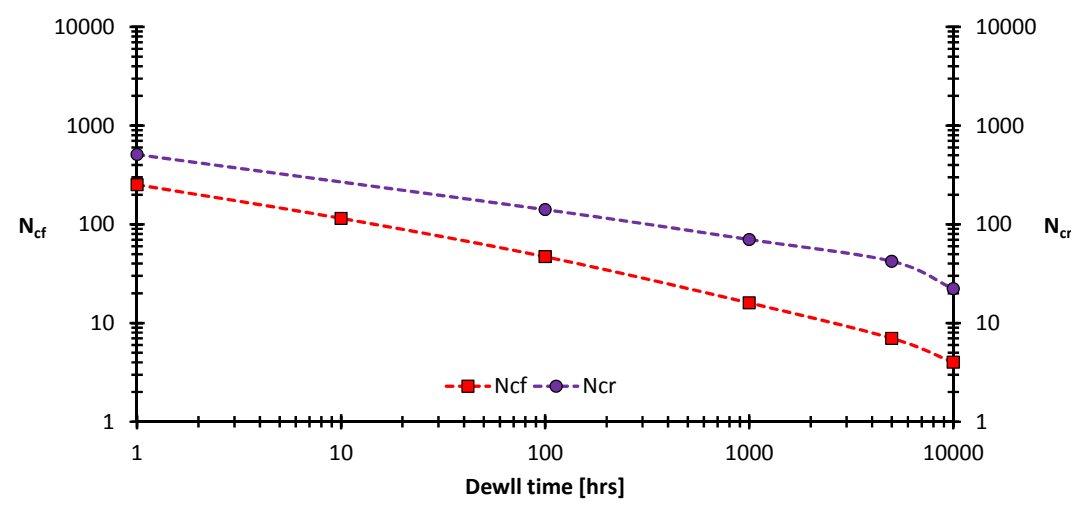

b)

$\varepsilon_{p}^{U L}$

$\Delta \varepsilon_{r}$
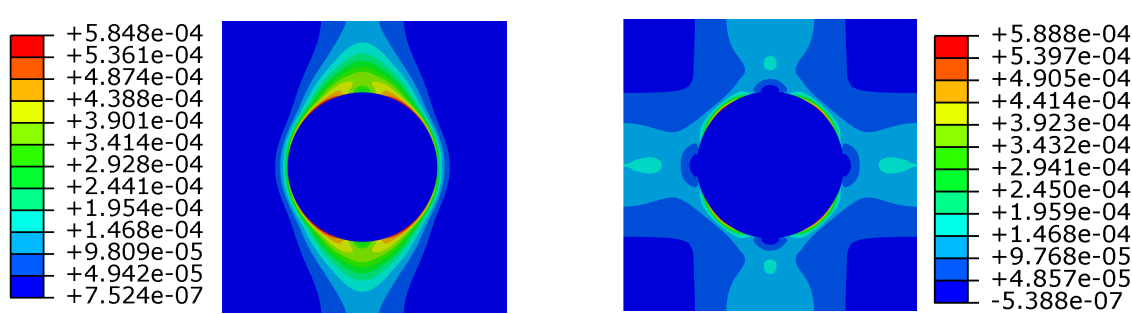

Fig. 19. a) Creep-fatigue life and creep ratchetting life against dwell time, b) contours of the plastic strain at unloading phase and the creepratchetting strain per cycle for a cyclic temperature of $175^{\circ} \mathrm{C}$ and a constant mechanical load 0.25 time the yield of the matrix.

\section{Conclusions}

This paper investigates the interactions between fatigue and creep damages of a fibre reinforced MMC subjected to a cyclic temperature and constant mechanical load by using the LMM extended DSCA with micromechanical modelling. The MMC is modelled using an idealised plain strain model, where both matrix and fibre materials are modelled as elastic-perfectly plastic. The time dependant creep behaviour is modelled using the Norton-Bailey relationship.

A detailed study on MMC responses to different cyclic load points within the shakedown limit is performed. The primary load level and dwell time are confirmed to be the two most important parameters for creep-fatigue interaction. When the dwell time is small enough (e.g. 1 hour) a closed hysteresis loop can be observed for a low level of primary load. Conversely when dwell time increases creep ratchetting become significant. The increasing 
dwell time increases the total strain range, by increasing the plastic strain increment during unloading phase, due to the stress relaxation during the creep dwell period. Once the steady state creep stress is reached at the end of the creep dwell no more increase of plastic strain increment is possible. Typically for a long dwell time (more than 1000 hours), creep ratchetting is present with an inelastic strain accumulation at each cycle, the magnitude of which increases almost linearly with the dwell time. When the primary load is zero, creep ratchetting does not take place for any thermal load level and dwell times.

In addition to these results, a discussion on the failure mechanisms is presented for the most critical cyclic load point $\left(\mathrm{B}_{2}\right)$, presenting a full unit cell view. The main contribution to the MMC damaging is the stress relaxation and redistribution during the dwell period, which makes it possible to yield regions which normally don't exhibit a plastic behaviour without the creep dwell. Overall, the life and integrity of MMC is reduced by the combined action of creep and fatigue damages, as well as the accumulated inelastic strain per cycle due to the creep ratchetting mechanism. At this high level of mechanical load, dwell time has a strong impact on the failure mechanism. For dwell times up to 1000 hours, the creep fatigue failure is dominated by creep damage. Otherwise for extremely long dwell times (up to 10000 hours), the monotonic creep rupture occurs.

The effect of temperature on creep ratchetting is also investigated, and it has been demonstrated that for a low temperature of $150^{\circ} \mathrm{C}$, creep ratchetting is dominant over the creep-fatigue interaction after a critical dwell period when a mechanical load is applied. Conversely at a higher temperature of $175^{\circ} \mathrm{C}$, the damage caused by creep ratchetting is less significant than the damage caused by creep fatigue interaction, where creep and fatigue damages are comparable for dwell times between 1 and 100 hours. However at such a higher temperature condition, when the dwell period is beyond 100 hours, creep damage dominates.

The accuracy and efficiency of the LMM extended DSCA for the evaluation of cyclic plastic creep behaviour of MMC has been confirmed by direct comparisons with a set of ABAQUS step-by-step analyses. All the comparisons demonstrate that LMM is capable of providing accurate solutions, with reduced computational efforts.

\section{Acknowledgements}

The authors gratefully acknowledge the support of the University of Strathclyde, the Royal Academy of Engineering, the Royal Society (IE140842), the International Cooperation and Exchange Project NSFC (11511130057) and the National Science Foundation for Distinguished Young Scholars of China (11325211) during the course of this work. All solutions provided in the work presented have been obtained using the finite element software ABAQUS.

\section{References}

[1] Manson, S, and Halford, GR, Fatigue and durability of metals at high temperatures, ASM International. 2009

[2] Ainsworth, R. R5: Assessment procedure for the high temperature response of structures, British Energy Generation Ltd, 3. 2003.

[3] American Society of Mechanical Engineers, B, and Pressure Vessel, C. ASME boiler \& pressure vessel code : an international code, New York, N.Y. American Society of Mechanical Engineers. 2007.

[4] Chen H, Chen W, and Ure J, A Direct Method on the Evaluation of Cyclic Steady State of Structures With Creep Effect. J Pres Ves Tech, 2014;136(6):061404-061404.

[5] Chen, H., and Ponter, AR, Linear Matching Method on the evaluation of plastic and creep behaviours for bodies subjected to cyclic thermal and mechanical loading. Int J Numer Meth Eng 2006;68(1):13-32.

[6] Bree J, Incremental growth due to creep and plastic yielding of thin tubes subjected to internal pressure and cyclic thermal stresses. J Strain Anal Eng 1968;3(2):122-127.

[7] Fleming WJ, and Temis JM, Numerical simulation of cyclic plasticity and damage of an aluminium metal matrix composite with particulate $\mathrm{SiC}$ inclusions. Int J Fatigue 2002;24(10):1079-1088.

[8] Qing H. Automatic generation of 2D micromechanical finite element model of silicon-carbide/aluminum metal matrix composites: Effects of the boundary conditions. Mater Des 2013;44(0): 446-453.

[9] Qing, H. 2D micromechanical analysis of SiC/Al metal matrix composites under tensile, shear and combined tensile/shear loads. Mater Des 2013;51(0): 438-447.

[10] Echle R, and Voyiadjis GZ. Simulation of damage evolution in a uni-directional titanium matrix composite subjected to high cycle fatigue. Int J Fatigue 1999;21(9):909-923.

[11] Schneider Y, Soppa E, Kohler C, Mokso R, and Roos E. Numerical and experimental investigations of the global and local behaviour of an $\mathrm{Al}(6061) / \mathrm{Al} 2 \mathrm{O} 3$ metal matrix composite under low cycle fatigue. Procedia Engineering 2011;10(0):1515-1520. 
[12] Yuan MN, Yang YQ, Li C, Heng PY, and Li LZ, Numerical analysis of the stress-strain distributions in the particle reinforced metal matrix composite SiC/6064Al. Mater Des 2012;38(0):1-6.

[13] Guo S, Kang G, and Zhang J. Meso-mechanical constitutive model for ratchetting of particle-reinforced metal matrix composites. Int J Plasticity 2011;27(12):1896-1915.

[14] Baxevanis T, and Charalambakis N. A micromechanically based model for damage-enhanced creep-rupture in continuous fiber-reinforced ceramic matrix composites. Mech Mater 2010;42(5):570-580.

[15] Pandorf R, and Broeckmann C. Numerical simulation of matrix damage in aluminium based metal matrix composites. Comp Mater Sci 1998;13(1-3):103-107.

[16] Chen H, and Giugliano D, On the behaviour of fibre reinforce metal matrix composites under loading and thermal cycling conditions, 20th International Conference on Composite MaterialsCopenhagen. 2015.

[17] Chen HF, and Ponter ARS. On the behaviour of a particulate metal matrix composite subjected to cyclic temperature and constant stress. Comp Mater Sci 2005;34(4):425-441.

[18] Gorash Y, and Chen H. Creep-fatigue life assessment of cruciform weldments using the linear matching method. Int J Pres Ves Pip 2013;104(0):1-13

[19] Gorash Y, and Chen H. On creep-fatigue endurance of TIG-dressed weldments using the linear matching method. Eng Fail Anal 2013;34(0):308-323

[20] Gorash Y, and Chen H, A parametric study on creep-fatigue endurance of welded joints. Proc Appl Math Mech 2013;13(1):73-74

[21] Maximov JT, Duncheva GV, Anchev AP, and Ichkova MD. Modeling of strain hardening and creep behaviour of 2024T3 aluminium alloy at room and high temperatures. Comp Mater Sci 2014;83(0):381-393.

[22] Kapoor A. A re-evaluation of the life to rupture of ductile metals by cyclic plastic strain. Fatigue Frac Eng M 1994;17(2):201-219. 